\section{ZEW}

Zentrum für Europäische Wirtschaftsforschung GmbH

Centre for European Economic Research

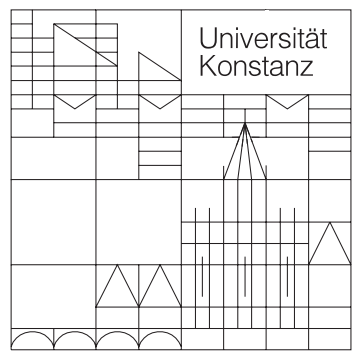

Rechts-, Wirtschafts- und Verwaltungswissenschaftliche Sektion

Fachbereich

Wirtschaftswissenschaften

Diskussionspapiere der DFG-

Forschergruppe (Nr.: 3468269275):

Heterogene Arbeit: Positive und Normative Aspekte der Qualifikationsstruktur der Arbeit

Dirk Schindler

Tuition Fees and the Dual Income Tax The Optimality of the Nordic Income Tax System Reconsidered

June 2007 
Diskussionspapier der Forschergruppe (Nr.: 3468269275) "Heterogene Arbeit: Positive und Normative Aspekte der Qualifikationsstruktur der Arbeit"

Nr. 07/08, June 2007

\title{
Tuition Fees and the Dual Income Tax - The Optimality of the Nordic Income Tax System Reconsidered
}

\section{Dirk Schindler}

\author{
Universität Konstanz \\ Fachbereich Wirtschaftswissenschaften \\ Fach D133 \\ 78457 Konstanz \\ Germany \\ mail: Dirk.Schindler@uni-konstanz.de \\ phone: $+49-7531-88-3691$ \\ fax: $\quad+49-7531-884101$
}

\section{Zusammenfassung:}

Abstract: We examine the optimal tax and education policy in case of a dual income tax and a publicly provided education system with endogenous tuition fees. In a Nielsen and Sørensen (1997) type OLG framework, we show that tuition fees and progressive labor taxation are (largely) equivalent instruments, even when labor supply is endogenous. Hence, there exists a large variety of Second-best optimal tax and education systems - including the Nordic one. Moreover, education subsidies and progressive taxation turn out to be "Siamese Twins" on pure efficiency grounds. 


\title{
Tuition Fees and the Dual Income Tax -
}

\section{The Optimality of the Nordic Income Tax System Reconsidered}

\author{
Dirk Schindler* \\ Universität Konstanz ${ }^{\dagger}$
}

June 07, 2007

\begin{abstract}
We examine the optimal tax and education policy in case of a dual income tax and a publicly provided education system with endogenous tuition fees. In a Nielsen and Sørensen (1997) type OLG framework, we show that tuition fees and progressive labor taxation are (largely) equivalent instruments, even when labor supply is endogenous. Hence, there exists a large variety of Second-best optimal tax and education systems - including the Nordic one. Moreover, education subsidies and progressive taxation turn out to be 'Siamese Twins' on pure efficiency grounds.
\end{abstract}

JEL Classification: H21, H24, I28

Keywords: optimal income taxation, human capital investment, tuition fees

${ }^{*}$ The author wants to thank Bernd Genser, Bas Jacobs, and Mathias Kifmann for valuable comments and suggestions.

${ }^{\dagger}$ Corresponding author: Dirk Schindler, Universität Konstanz, Fach D 133, 78457 Konstanz, Germany; email: Dirk.Schindler@uni-konstanz.de; phone +49-7531-883691, fax $+49-7531-884101$. 


\section{Introduction}

In the early 1990s, the Nordic countries introduced a dual income tax system, which regards labor income and capital income as two separated tax bases. This tax base split can be justified on efficiency grounds: Introducing an additional degree of freedom in tax instruments reduces the excess burden generated by a comprehensive income tax (see, e.g., Atkinson and Sandmo, 1980). However, such models usually restrict the analysis to proportional labor taxation, whereas the Nordic countries maintained their highly progressive labor taxation.

In their seminal paper, Nielsen and Sørensen (1997) show that such a progressive tax structure is optimal, if there is a flat tax on income from real capital. While the latter distorts the savings decision, a proportional labor tax replicates a cash-flow tax on human capital returns, which leaves the education decision undistorted. This cannot be optimal in a Secondbest world. Hence, the overall excess burden can be lowered by an adequate distortion of human capital formation via progressive labor taxation. Nielsen and Sørensen, however, assume that there are no direct costs of education, which allows them to neglect the education sector. They argue that this can be justified by the absence of tuition fees in the Nordic countries.

Contrary to this view, the reform of tuition fees in the U.K. by the government of Tony Blair and the debate in Central Europe, especially in Germany, about introducing tuition fees as well as the US-way of financing education show that tuition fees are a relevant strategic instrument variable for the government. If, however, tuition fees are in use, direct costs of education should be taken into account and the following questions emerge: Is the Nordic tax system and its progressive taxation still optimal, if the government has access to tuition fees/subsidies? Hence, is the Nielsen and Sørensen-result robust? Moreover, an ongoing question is the linkage between the optimal tax and education policy and the variety observed across countries. Can the negative correlation of progressive taxation and tuition fees be explained by an optimal taxation approach?

Nerlove et al. (1993) examine a model, where all educational costs are 
direct costs and not tax deductable. They find that a linear comprehensive income tax discriminates against investment in human capital. Thus, a progressive taxation is not necessary. However, their setting cannot easily be extended to cover a broader set of instruments and to answer the questions, posed above. ${ }^{1}$

Jacobs and Bovenberg (2005), on the contrary, examine a model, which contains a rich set of tax instruments. In the case, where there are both verifiable investment in human capital (e.g., time spent for learning), which is tax-deductible and can be additionally subsidized, and non-verifiable inputs into education, they show that it depends on the substitution elasticity in the human capital production function, whether verifiable inputs should be subsidized or should be taxed by a kind of tuition fee. In any case, the optimal tax rate on capital income is positive in order to alleviate the distortion in human capital accumulation, created by a labor tax, which distorts the use of non-verifiable inputs in education. In a nutshell, there is a tradeoff between distortions in the aggregate level of (financial) savings, in the aggregate learning, and in the composition (of inputs) of learning. However, Jacobs and Bovenberg (2005) restrict their analysis to a linear labor tax, and, hence, leave the linkage between progressive (labor) taxation and tuition fees/education subsidies a pending, open question.

We extend, therefore, the Nielsen and Sørensen model and incorporate a sector with costly education services. This can be regarded as a short-cut for a publicly provided education (university) system, where the students either have to pay tuition fees or receive subsidies in each semester. This reflects quite well features of the European higher education systems.

We show that the Nordic tax system remains still optimal, but it is only one possible solution in a bundle of tuition fees/tax rates programmes, because tuition fees and progressive labor taxation turn out to be equivalent instruments. The bundle of optimal systems covers also the US-system.

Moreover, we want to link the analysis to recent work on educational

\footnotetext{
${ }^{1}$ Moreover, the results should be handled with care, due to a positive externality in human capital investment, embedded in the model, and a computational error. See Echevarria and Iza (1997).
} 
economics and public finance. The main intuition, thereby, is that, in principle, such subsidies alleviate distortions in (the composition of) learning, and reduce the negative incentive effects of labor taxation - and therefore allow for more efficient redistribution. ${ }^{2}$

In the present paper, we show that education subsidies and progressive labor taxation can be 'Siamese Twins' on pure efficiency grounds without using any redistributive argument. This avoids any problem with self-selection, and the modelling of different types of households.

The remainder of the paper is organized as follows: The next section presents some stylized facts concerning the internationally observed variety of tax and education policy programmes. Section 3 describes the model, including an explicit education sector and direct learning costs. In section 4, the decision problem of the government is stated. We examine the benchmark case of inelastic labor supply in section 5, and derive the optimal tax structure in the general case of endogenous labor supply in section 6. Detailed results under more restrictive assumptions are discussed in Sections 7 and 8. Section 9 concludes.

\section{International Tax and Education Systems}

There is a large variety in both the educational sector and the tax systems across the countries. The differences can be summarized in three different ways: the Nordic one (i.e., Norway and Sweden), the Central Europe way (e.g., Germany and Austria), and the anglo-saxon one (the US and the U.K.).

In all European countries, including hereby also the U.K., the higher education sector is publicly financed. In the US, a lot of universities, and most of the leading ones, are private institutions. Nonetheless, a large part of the higher educational sector is also financed by the government, and it seems to be likely that also private universities profit from these subsidies. Although the share of state government contributions to higher education has declined in the US, it accounted in 1995 still for about $24 \%$ for all institutions

\footnotetext{
${ }^{2}$ See, e.g., Bovenberg and Jacobs (2005) vs. Wigger (2004).
} 
and for $36 \%$ in public universities. ${ }^{3}$ Bovenberg and Jacobs (2005, Table 1) display a marginal subsidy rate of $33.9 \%$ for the US and of $67.7 \%$ for the U.K., which are still 'low' in comparison to $91.8 \%$ in Germany, and $96.7 \%$ in Austria, or to $88.1 \%$ in Sweden, and $96.2 \%$ in Norway, but by far not marginal.

These differences in public finance for higher education are mirrored also in the reliance on tuition fees. In the Nordic countries there are no tuition fees at all. In Central Europe, tuition fees have not been common, but in 2001 Austria introduced a fee of about 750 Euro per year, and Germany has followed in 2006 by introducing fees at a level of about 1,000 Euro per year. Moreover, in both countries, these fees are seen as starting point, and a further increase is to be expected. The US, instead, already heavily rely on tuition fees. Tuition fees there cover $27 \%$ of the costs in all higher education institutions, and about $18 \%$ in public ones. ${ }^{4}$ In the U.K., the Blairgovernment introduced tuition fees in 1997 , and students had to pay $1,000 £$ per year. After an amendment in 2004, fees up to $3,000 £$ are possible, now.

Turning to the tax systems, we can note: the Nordic way incorporates high marginal tax rates on labor income, and (very) strong progressivity, as already indicated in Nielsen and Sørensen (1997). In Central Europe, the tax schedule exhibits traditionally strong progressivity, but not as strong as in the Nordic countries. In, e.g., Germany, the entry tax rate is $15 \%$, and the highest marginal rate amounts $42 \% .^{5}$ The US-way is having only a slight progressive taxation, at least in the most relevant range of income. In the US, according to the IRS tax rate schedule 2005, the statutory marginal tax rate begins at $10 \%$ and increases until $35 \%$, which seems to be not much different from Germany, but the increase in Germany starts at an income of about 7,500 Euro, and ends at about 55,000 Euro, whereas the US marginal tax rate is $15 \%$ at 7,300 US-\$ income, and is not higher than $28 \%$ until 150,000 US-\$. The top peak of $35 \%$ is reached only at incomes above 326,000 US-\$. The U.K. is somewhere in between the Central Europe tradition and the

\footnotetext{
${ }^{3}$ See Wildasin (2000), p. 91.

${ }^{4}$ See Wildasin (2000), p. 91.

${ }^{5}$ Since 2007 , the highest German marginal income tax rate is in fact $45 \%$, but only for an income above 250,000 Euro.
} 
US-way. There is a basic rate of $22 \%$ until about $30,000 £$, and a higher rate of $40 \%$ for income above this threshold. ${ }^{6}$

Moreover, it seems to be the case that the capital tax rate is (virtually) independent of the progressivity in labor taxation. This statement fits perfectly with the tax systems in the Nordic countries, where a dual income tax is in power. Several Central Europe countries (i.e., Austria, Belgium, Italy, and Poland) has set major steps towards a dual income tax, and introduced final withholding taxes on capital income. In Germany, the effective capital taxation is already much lower than the tax burden on labor income and a pure flat rate on capital income is introduced in 2009. Although the anglosaxon countries (i.e., the US and the U.K.) still follow ipso jure the fiction of comprehensive income taxation, all these countries de facto also exhibit strong deviations from this principle: there are many loopholes, and capital income is taxed in a very favorable way. Thus, reforms in labor income taxation really should not have much effect on the effective capital tax rates, and capital taxation is independent of labor taxes.

In a nutshell, we observe a negative correlation of tuition fees and the degree of progressivity in international education and tax systems - whereby the capital taxation is positive, but independent of labor taxation.

\section{The Model}

For our analysis, we extend the Nielsen and Sørensen (1997) overlapping generations model, where representative households live for two periods, and where their mass is normalized to one.

In a small open economy, the business sector produces a homogenous good $Y$ whose price is normalized to unity. A perfectly integrated world capital market and a constant-returns-to-scale per-capita production function $y=$ $f(k)$ with $k$ as capital intensity determine the real interest rate as $f^{\prime}(k)=r$ and the wage per unit of effective labor by $W=f(k)-r k$. Hence, pre-tax factor prices are independent of the domestic tax system.

\footnotetext{
${ }^{6}$ We neglect the lower rate of $10 \%$ for income below $2,000 £$.
} 
The representative consumer has a utility function $U=U\left(C_{1}, C_{2}, l_{1}, l_{2}\right)$ with positive, but decreasing marginal utility, $U_{i}>0, U_{i i}<0$, where $C_{i}$ is consumption in period $i=1,2$, and $l_{i}$ represents leisure in period $i$.

In the first period, the household is provided with one unit of time, consumes a share $l_{1}$ as leisure, and spends a share of $E \geq 0$ for education. The remaining time $1-l_{1}-E$ is supplied as unskilled labor and earns a wage rate $W$ per unit. In the second period, the household has one unit of time, which is spent either on leisure, $l_{2}$, or on working time $L_{2}=1-l_{2}$. Working time translates into skilled labor supply, $g(E) \cdot\left(1-l_{2}\right)$, according to a concave human capital formation function $g(E)$ with $g(0)=1, g^{\prime}(E)>0$ and $g^{\prime \prime}(E)<0$.

The tax system implemented is a dual income tax. The wage income below an exogenous threshold $X \cdot W$ is taxed at a basic tax rate $t_{1}$. Wage income above this level is liable to a marginal surcharge tax rate $t_{2}$. We assume that maximum wage income of unskilled (or "raw") labor is less than the threshold, $W \leq X \cdot W$, which implies that unskilled labor is entirely taxed at rate $t_{1}$. Moreover, effective skilled labor income in the second period is assumed to be higher than this threshold, $W \cdot g(E) \cdot\left(1-l_{2}\right)>X \cdot W$, and a skilled worker is faced with a marginal tax rate $t_{2}$. This can be guaranteed by assuming that the marginal productivity of the first time units invested in education is high enough, in order to secure an inner solution for E. Capital income is taxed at a proportional rate $\tau$.

Contrary to Nielsen and Sørensen (1997), we assume that forgone earnings are not the only private cost component of investing in human capital. There is also a price $p_{B}$, set by the government and to be paid for each unit of $E$ spent for education. $p_{B}>0$ can be interpreted as tuition fee, which has to be paid for each semester, $E$, spent at university in the first period of life. The reasoning behind is that, in our model, higher education can only be acquired at university, but visiting the university is exclusive. ${ }^{7}$

\footnotetext{
${ }^{7}$ Bas Jacobs has pointed out to the author that the present model is very similar to the first, but unpublished version of the 'Siamese Twins,' whereby our paper is though less general by assuming homogenous households, it is more general by using general utility and production functions. This avoids, i.e., weak separability in leisure and education, which drives some of the results in Bovenberg and Jacobs (2001).
} 
Moreover, the university system causes resource costs. These consist of fixed costs, $\bar{H}$, and of variable costs, $H^{v}$, which depend on the number of semesters, a student spends at university: $H^{v}(E)=p_{R} \cdot E$. All resource costs are financed by the government, which can levy fees on students according to their attendance.

The fee can also have the character of an education subsidy. If the tuition fee is less than the real resource costs in the educational sector per student and semester, the difference must be provided by the government via tax revenue. This is the case if $p_{B}$ is low (especially if $p_{B}<p_{R}$ ) or even zero, and forces the government to pay an implicit education subsidy. Moreover, $p_{B}$ can turn negative and the tuition fee gets the character of a direct education subsidies. For simplicity, we assume that tuition fees cannot be deducted from taxable income. ${ }^{8}$

Taken together, first period savings, $S$, of an household are

$$
S=\left(1-t_{1}\right) W \cdot\left(1-l_{1}-E\right)-p_{B} \cdot E-C_{1} .
$$

Second period consumption, $C_{2}$, is financed by after tax wage income, savings and the after tax interest income. Taking into account the tax system described above, this implies

$$
C_{2}=[1+r(1-\tau)] \cdot S+\left(1-t_{2}\right) W \cdot g(E) \cdot\left(1-l_{2}\right)+\left(t_{2}-t_{1}\right) \cdot X \cdot W .
$$

Consolidation gives the intertemporal budget constraint

$$
C_{1}+p \cdot C_{2}+p_{B} \cdot E=w_{1} \cdot\left(1-l_{1}-E+p X\right)+p \cdot w_{2} \cdot\left[g(E) \cdot\left(1-l_{2}\right)-X\right]
$$

We introduce $p=\frac{1}{1+r(1-\tau)}$ as the price of future consumption, $w_{1}=\left(1-t_{1}\right) \mathrm{W}$ as the after tax wage for unskilled labor and $w_{2}=\left(1-t_{2}\right) W$ as the marginal after tax wage for skilled workers.

Maximizing its lifetime utility, $U$, subject to the budget constraint (3),

\footnotetext{
${ }^{8}$ This assumption reflects the German legislation, where neither students nor their parents can deduct such expenses on education.
} 
the individual acts according to the rearranged first order conditions

$$
\begin{aligned}
\frac{U_{1}}{U_{2}} & =\frac{1}{p}=1+r(1-\tau), \\
\frac{U_{l_{1}}}{U_{l_{2}}} & =\frac{w_{1}}{p \cdot w_{2} \cdot g(E)}, \\
p_{B}+w_{1} & =p \cdot w_{2} \cdot g^{\prime}(E) \cdot\left(1-l_{2}\right) .
\end{aligned}
$$

Combining (4) and (6) we get

$$
\left(\frac{w_{2} \cdot g^{\prime}(E) \cdot\left(1-l_{2}\right)}{w_{1}+p_{B}}\right)-1=r(1-\tau)=\frac{U_{1}}{U_{2}}-1=\rho .
$$

Optimal allocation of consumption and time equates the marginal rate of time preference, $\rho=\frac{U_{1}}{U_{2}}-1$, and the effective return on education to the after tax interest rate. Equation (7) replicates the result of Nielsen and Sørensen (1997) for a tuition fee of zero, $p_{B}=0$. In our model, direct education costs, $p_{B}>0$, reduce the effective marginal return on human capital and, ceteris paribus, decrease investment in education.

Optimal consumption and optimal time spent on education and on leisure can be written as

$$
\begin{aligned}
C_{i} & =C_{i}\left(w_{1}, w_{2}, p_{B}, p, X\right), \quad E=E\left(w_{1}, w_{2}, p_{B}, p, X\right), \\
l_{i} & =l_{i}\left(w_{1}, w_{2}, p_{B}, p, X\right) .
\end{aligned}
$$

Neglecting the tax instruments $\tau$ and $X$, which are regarded as fixed exogenously in the following government decision problem, and paying attention to the effects of income tax rates on the wage rates $w_{1}$ and $w_{2}$, we can simplify the representation of the indirect utility function to

$$
V\left(w_{1}, w_{2}, p_{B}\right)=U\left(C_{1}\left(w_{1}, w_{2}, p_{B}\right), C_{2}\left(w_{1}, w_{2}, p_{B}\right), l_{1}\left(w_{1}, w_{2}, p_{B}\right), l_{2}\left(w_{1}, w_{2}, p_{B}\right)\right) .
$$

Introducing $\lambda$ as the marginal utility of income, the Envelope theorem im- 
plies

$\frac{\partial V}{\partial w_{1}}=\lambda \cdot\left(1-l_{1}-E+p X\right) ; \quad \frac{\partial V}{\partial w_{2}}=\lambda \cdot p \cdot\left[g(E) \cdot\left(1-l_{2}\right)-X\right] ; \quad \frac{\partial V}{\partial p_{B}}=-\lambda \cdot E$.

\section{Governmental Optimization Problem}

Following Nielsen and Sørensen (1997), we analyze a government decision problem, which keeps the level of public expenditure, $\bar{G}$, the capital tax rate, $\tau$, and the threshold for the income tax bracket, $X$, fixed.

The government raises the necessary funds by using the exogenous capital income tax, and by setting both the tax rates on labor income, $t_{1}$ and $t_{2}$, and the price for education (tuition fees), $p_{B}$. To assume a positive capital tax rate in an OLG model seems to be justifiable as long as the utility function is not (weakly) separable in consumption and leisure (see Atkinson and Sandmo, 1980). A positive capital taxation in a Ramsey economy spreads the tax burden on labor supply and savings, and reduces overall excess burden.

The government implements a Pareto-improving tax reform: in order to avoid windfall gains and/or losses, the old generation still faces the old tax rules, but the young and all following generations are liable to the new, post-reform tax parameters. Thus, the government chooses the tax rates on labor income and the tuition fees in order to maximize the welfare of a representative consumer, keeping the utility of the current old generation constant, subject to the government's budget constraint.

This allows to implement the new steady-state tax parameters within one period, but requires a transition scheme in order to fulfill both constraints simultaneously. Such a Pareto-improving mechanism, which does not affect the welfare of the current old, can be achieved by using a one-time debt policy in the transition period. ${ }^{9}$

Let the superscript "o" represent the old values of the tax rates and assume that the government issues (or retires) debt, $D$, in order to keep the

\footnotetext{
${ }^{9}$ See Nielsen and Sørensen (1997), pp. 318. The advantage of this approach is that one does not focus on steady-state utility only.
} 
new, post-reform tax parameters constant for all time. Then, the government budget constraint in the period, when the tax reform is enacted, can be written as

$$
\begin{aligned}
& t_{2}^{o} W \cdot g\left(E\left(w_{1}^{o}, w_{2}^{o}, p_{B}^{o}\right)\right) \cdot\left(1-l_{2}\left(w_{1}^{o}, w_{2}^{o}, p_{B}^{o}\right)\right)-\left(t_{2}^{o}-t_{1}^{o}\right) \cdot X \cdot W+(10) \\
& \tau r \cdot S\left(w_{1}^{o}, w_{2}^{o}, p_{B}^{o}\right)+t_{1} W \cdot\left[1-l_{1}\left(w_{1}, w_{2}, p_{B}\right)-E\left(w_{1}, w_{2}, p_{B}\right)\right]+ \\
& p_{B} \cdot E\left(w_{1}, w_{2}, p_{B}\right)+D=\bar{G}+\bar{H}+p_{R} \cdot E\left(w_{1}, w_{2}, p_{B}\right) .
\end{aligned}
$$

Keeping the tax parameters and the stock of governmental debt constant in all following periods, the budget restriction in each post-reform period is equal to

$$
\begin{aligned}
& t_{1} W \cdot\left[1-l_{1}\left(w_{1}, w_{2}, p_{B}\right)-E\left(w_{1}, w_{2}, p_{B}\right)\right]+ \\
& t_{2} W \cdot g\left(E\left(w_{1}, w_{2}, p_{B}\right)\right) \cdot\left(1-l_{2}\left(w_{1}, w_{2}, p_{B}\right)\right)- \\
& \left(t_{2}-t_{1}\right) \cdot X \cdot W+\tau r \cdot S\left(w_{1}, w_{2}, p_{B}\right)+p_{B} \cdot E\left(w_{1}, w_{2}, p_{B}\right) \\
= & \bar{G}+\bar{H}+p_{R} \cdot E\left(w_{1}, w_{2}, p_{B}\right)+r \cdot D .
\end{aligned}
$$

Using the definition of the savings function in (1), we can substitute $D$ and end up with the consolidated intertemporal budget constraint of the government

$$
\begin{aligned}
& (1+r)\left(W-w_{1}\right)\left(1-l_{1}\left(w_{1}, w_{2}, p_{B}\right)-E\left(w_{1}, w_{2}, p_{B}\right)\right)+ \\
& \left(\frac{p_{B}}{p}-(1+r) p_{R}\right) \cdot E\left(w_{1}, w_{2}, p_{B}\right)+ \\
& \left(W-w_{2}\right) g\left(E\left(w_{1}, w_{2}, p, p_{B}\right)\right) \cdot\left(1-l_{2}\left(w_{1}, w_{2}, p_{B}\right)\right)+\left(w_{2}-w_{1}\right) \cdot X+ \\
& \tau r \cdot\left[w_{1}\left(1-l_{1}\left(w_{1}, w_{2}, p_{B}\right)-E\left(w_{1}, w_{2}, p_{B}\right)\right)-C_{1}\left(w_{1}, w_{2}, p_{B}\right)\right]=\bar{R},
\end{aligned}
$$

where $\bar{R}=(1+r)(\bar{G}+\bar{H})-r \cdot\left[t_{2}^{o} W \cdot g\left(E\left(w_{1}^{o}, w_{2}^{o}, p_{B}^{o}\right)\right) \cdot\left(1-l_{2}\left(w_{1}^{o}, w_{2}^{o}, p_{B}^{o}\right)\right)-\right.$ $\left.\left(t_{2}^{o}-t_{1}^{o}\right) \cdot X \cdot W+\tau r \cdot S\left(w_{1}^{0}, w_{2}^{0}, p_{B}^{0}\right)\right]$ is the exogenous net expenditure per period.

The optimization problem is as follows:

$$
\max _{w_{1}, w_{2}, p_{B}} V\left(w_{1}, w_{2}, p_{B}\right) \quad \text { subject to } \quad(13) .
$$


Using (9) and denoting the Lagrange parameter of (13), which measures the marginal loss of utility by an additional unit of tax revenue, by $\mu$, the first order conditions are

$$
\begin{aligned}
\lambda\left(1-l_{1}-E+p\right)= & \mu\left[1 / p \cdot\left(1-l_{1}-E\right)+X+A \cdot \frac{\partial l_{1}}{\partial w_{1}}\right]+ \\
& \mu\left[\left(W-w_{2}\right) \cdot g(E) \cdot \frac{\partial l_{2}}{\partial w_{1}}+B \cdot \frac{\partial E}{\partial w_{1}}+\tau r \cdot \frac{\partial C}{\partial w_{1}}\right], \\
\left.\lambda p \cdot g(E) \cdot\left(1-l_{2}\right)-X\right]= & \mu\left[g(E) \cdot\left(1-l_{2}\right)-X+A \cdot \frac{\partial l_{1}}{\partial w_{2}}\right]+ \\
& \mu\left[\left(W-w_{2}\right) \cdot g(E) \cdot \frac{\partial l_{2}}{\partial w_{2}}+B \cdot \frac{\partial E}{\partial w_{2}}+\tau r \cdot \frac{\partial C_{1}}{\partial w_{2}}\right], \\
\lambda E= & \mu\left[\frac{E}{p}-A \cdot \frac{\partial l_{1}}{\partial p_{B}}\right]- \\
& \mu\left[\left(W-w_{2}\right) \cdot g(E) \cdot \frac{\partial l_{2}}{\partial p_{B}}+B \cdot \frac{\partial E}{\partial p_{B}}+\tau r \cdot \frac{\partial C_{1}}{\partial p_{B}}\right],
\end{aligned}
$$

where $A=(1+r)\left(W-w_{1}\right)+\tau r \cdot w_{1}=(1+r) \cdot W-w_{1} / p>0$, and $B=(1+r)\left(W-w_{1}\right)-p_{B} / p+(1+r) p_{R}-\left(W-w_{2}\right) g^{\prime}(E) \cdot\left(1-l_{2}\right)+\tau r \cdot w_{1}$.

Dividing equations (14) and (16) by (15), rearranging, and summing up the reduced form results in

$$
\begin{aligned}
& A \cdot\left[\left(1-l_{1}+p X\right) \frac{\partial l_{1}}{\partial w_{2}}+p\left[g(E)\left(1-l_{2}\right)-X\right]\left(\frac{\partial l_{1}}{\partial p_{B}}-\frac{\partial l_{1}}{\partial w_{1}}\right)\right]+ \\
& \left(W-w_{2}\right) g(E) \cdot\left[\left(1-l_{1}+p X\right) \frac{\partial l_{2}}{\partial w_{2}}+p\left[g(E)\left(1-l_{2}\right)-X\right]\left(\frac{\partial l_{2}}{\partial p_{B}}-\frac{\partial l_{2}}{\partial w_{1}}\right)\right]+ \\
& B \cdot\left[\left(1-l_{1}+p X\right) \frac{\partial E}{\partial w_{2}}+p\left[g(E)\left(1-l_{2}\right)-X\right]\left(\frac{\partial E}{\partial p_{B}}-\frac{\partial E}{\partial w_{1}}\right)\right]+ \\
& \tau r \cdot\left[\left(1-l_{1}+p X\right) \frac{\partial C_{1}}{\partial w_{2}}+p\left[g(E)\left(1-l_{2}\right)-X\right]\left(\frac{\partial C_{1}}{\partial p_{B}}-\frac{\partial C_{1}}{\partial w_{1}}\right)\right]=0
\end{aligned}
$$

\section{The Case of Inelastic Leisure Demand}

Let us first consider the benchmark case that leisure demand is entirely inelastic, and $l_{1}=l_{2}=0$. This implies that first-period labor supply solely depends on the time spent for education, $L_{1}=1-E$, and second-period 
labor supply is inelastic, $L_{2}=1$. Moreover, let us assume without loss of generality $X=1$. In this case, the first two lines in equation (17) vanish, and we can use ${ }^{10}$

$$
(1+p) \cdot \frac{\partial C_{1}}{\partial w_{2}}-p \cdot[g(E)-1] \cdot\left(\frac{\partial C_{1}}{\partial w_{1}}-\frac{\partial C_{1}}{\partial p_{B}}\right)=0
$$

Thus, we remain with

$$
B \cdot\left[(1+p) \cdot \frac{\partial E}{\partial w_{2}}-p \cdot[g(E)-1] \cdot\left(\frac{\partial E}{\partial w_{1}}-\frac{\partial E}{\partial p_{B}}\right)\right]=0,
$$

and because of $\frac{\partial E}{\partial w_{2}}>0$ and $\frac{\partial E}{\partial w_{1}}=\frac{\partial E}{\partial p_{B}}<0$ (see also the appendix), this implies

$$
B=(1+r)\left(W-w_{1}\right)-\frac{p_{B}}{p}+(1+r) p_{R}-\left(W-w_{2}\right) g^{\prime}(E)+\tau r \cdot w_{1}=0
$$

Using $p=\frac{1}{1+r(1-\tau)}$, we can rearrange the optimality condition in order to get

$$
B=(1+r) W-\frac{w_{1}+p_{B}}{p}+(1+r) p_{R}-\left(W-w_{2}\right) g^{\prime}(E)=0 .
$$

Hence, one instrument is redundant and we can either use a progressive tax system or tuition fees - or a mix of both, as $w_{1}$ and $p_{B}$ are linearly dependent. ${ }^{11}$

Moreover, taking into account the household's first order condition

$$
w_{1}-p \cdot w_{2} \cdot g^{\prime}(E)+p_{B}=0,
$$

we end up with

$$
1+r=g^{\prime}(E)-(1+r) \frac{p_{R}}{W}
$$

In the optimum, the user cost of (real) capital shall be equal to social marginal productivity of human capital. This can be seen as enforcing production

\footnotetext{
${ }^{10}$ See the appendix for a proof using comparative-statics and the households FOC.

${ }^{11}$ Using a slightly different optimization approach, it can be shown that there are two optimality conditions, which are simultaneously fulfilled. Hence, one of them is redundant.
} 
efficiency in sense of Diamond and Mirrlees (1971), given a fully specified set of instruments.

If we use $w_{i}=\left(1-t_{i}\right) W$, substitute $g^{\prime}(E)=1+r+(1+r) \frac{p_{R}}{W}$ in $(21)$, and rearrange, we achieve

$$
t_{2}-t_{1}=\frac{\tau r}{1+r} \cdot\left(1-t_{1}\right)-\frac{p_{B}}{W} \cdot \frac{1+r(1-\tau)}{1+r}+\frac{p_{R}}{W} \cdot\left(1-t_{2}\right) .
$$

We can reproduce the Nielsen and Sørensen-result, $t_{2}>t_{1}$ in case of $\tau>0$, if we set $p_{B}=0$, and assume that there are no additional resource costs of education, $p_{R}=0$.

The optimal tax rule can be interpreted on pure efficiency grounds in at least three ways.

First, the first order condition and the comparative-static analysis show that it is equivalent to use either tuition fees or a progressive (labor) income tax system. High tuition fees require a less progressive labor taxation and vice versa. Hence, the Nordic tax system, accompanied by no tuition fees for a publicly provided education system is an optimal (extended) tax regime and still in line with the results in Nielsen and Sørensen (1997). However, the anglo-saxon way of (high) tuition fees and a less progressive tax system can be also optimal on efficiency grounds. Moreover, the result can have an implication for the current debate in Germany and Central Europe, if tuition fees should be introduced: On the one hand, introducing tuition fees should lead to a lower and especially less progressive labor taxation. On the other hand, direct education subsidies $\left(p_{B}<0\right)$, when young, can be, presumably, distributional neutral, if they are repaid by a progressive labor taxation, when the young generation leaves universities. ${ }^{12}$ This can be seen as a compulsory loan-system (or a kind of an obligatory graduate tax). ${ }^{13}$ However, given the equivalence result, there is another decisive factor to be

\footnotetext{
${ }^{12}$ Distributional neutrality should require that the surcharge on high labor incomes is only paid by highly educated workers.

${ }^{13}$ See, e.g., García-Peñalosa and Wälde (2000), who also use inelastic leisure demand, but additionally rely on lump-sum taxation. Compared to this, a progressive labor taxation should mitigate the efficiency-equity trade-off, if there are ex-post heterogenous individuals.
} 
considered: mobility. If international labor force mobility is high, there can be an incentive to study in countries with no tuition fees and work in low-tax countries later on. All these aspects seem often to be neglected - at least in the German debate.

Second, the equivalence result is an analog to the consumption-oriented capital taxation. There, capital can either be taxed front-loaded, using interest adjustment and taxing only labor income, or back-loaded, using saving allowances for labor income and taxing principal and returns, when the savings are consumed in later periods (see, e.g., Rose, 1999). In our setting of tuition fees and labor taxation, moreover, it is also possible to have a positive tax burden on investment in (human) capital. Only in a world without tuition fees and without progressive taxation, the result of a neutral consumption-oriented (or cash-flow) taxation of real capital is reproduced.

Third, there is a strong linkage to the literature on financing education and redistributive aspects. Bovenberg and Jacobs (2005) state that education subsidies and redistribution (via progressive labor taxation) are 'Siamese Twins' - and create a very seminal metaphor. ${ }^{14}$ A more redistributive tax system can be achieved by using education subsidies, because the latter enhance efficiency by alleviating or even eliminating tax distortions induced by redistribution, i.e, in the accumulation of human capital. Their view is challenged by Wigger (2004), who uses an optimal taxation framework with two types of households. Only one type profits from investment in human capital. Wigger shows that the welfare-improving effect of education subsidies can be validated in case of linear labor taxation, whereas, it would not hold, if an optimal non-linear tax regime is implemented. However, it seems that his results are driven by the 'no-marginal-tax-at-the-top' result, which is sensitive in the modelling of types, and may change, when there is a continuum of different (ability) types.

In our setting, there prevails a very similar result as in Bovenberg and Jacobs (2005), but without using distributive arguments. We can state that, following the reasoning above, education subsidies and progressive labor taxation are 'Siamese Twins' even on pure efficiency grounds, if distortions in

\footnotetext{
${ }^{14} \mathrm{~A}$ similar argument is also, and already, brought forward in Trostel (1996).
} 
human capital by a capital taxation shall not be countered by tuition fees. Thus, redistributive concerns are, although sufficient, not necessary for the twin-result.

Contrary to Nielsen and Sørensen (1997), moreover, our results do not hinge on a positive capital tax rate $\tau$. In their model, $\tau=0$ implies a First-best solution, given exogenous labor supply, and requires a proportional labor taxation, $t_{1}=t_{2}$. In our special case, $\tau=0$ also implies a Firstbest optimum, because the savings decision is not distorted, but it does not require proportional labor taxation. Using $\tau=0$ in (24) and recognizing that progressive labor taxation implies $t_{2}>t_{1}$, this is still optimal, if either not all resource costs are financed by tuition fees, $\frac{p_{B}}{W} \cdot \frac{1+r(1-\tau)}{1+r}<\frac{p_{R}}{W} \cdot\left(1-t_{2}\right)$, or if education is even directly subsidized, $p_{B}<0$. In this case, (indirect or direct) education subsidies guarantee efficiency, because they eliminate the labor tax-induced distortions in human capital formation.

Taken together, we showed that the result by Nielsen and Sørensen is still valid, but it is not really robust, if an education sector is modelled and tuition fees are introduced as additional instrument: Incorporating tuition fees creates a bundle of optimal policies. Progressive labor taxation and no fees is only one possibility. However, two questions force on: First, is there any economic reasoning for subsidizing education (implicitly) on the one hand and for taxing human capital returns simultaneously via progressive labor taxation on the other hand? ${ }^{15}$ Second, do the results still hold, if we allow for elastic leisure demand? These questions will be considered in the next sections.

\section{Optimal Tax and Education Policies}

In order to examine the optimality condition (17) with endogenous labor supply, we use the Slutsky equations and separate substitution and income

\footnotetext{
${ }^{15}$ Of course, such a strategy is relevant in case of capital market imperfection. However, in our model, we assumed perfect capital markets, and hence, these imperfections should not be used as a justification for a 'no-fee-system' in our context.
} 
effects. It is worth while to restate the household's budget constraint as

$C_{1}+p \cdot C_{2}+p_{E}\left(w_{1}, p_{B}\right) \cdot E+p_{l_{1}}\left(w_{1}\right) \cdot l_{1}+p_{l_{2}}\left(w_{2}\right) \cdot l_{2}=p_{l_{1}}\left(w_{1}\right)+p_{l}\left(w_{2}\right)+\left(w_{1}-w_{2}\right) \cdot p X$,

whereby $p_{E}=w_{1}+p_{B}$ is the total price for consuming one unit of education $E, p_{l_{1}}=w_{1}$ is the price for first period leisure, and $p_{l_{2}}=p \cdot w_{2} \cdot g(E)$ is the effective (discounted) price of second-period leisure. For these prices, we have $\frac{\partial p_{E}}{\partial w_{1}}=\frac{\partial p_{E}}{\partial p_{B}}=\frac{\partial p_{l_{1}}}{\partial w_{1}}=1$ and $\frac{\partial p_{l_{2}}}{\partial w_{2}}=p \cdot g(E)$. We can now use the Slutsky decomposition for changes in the prices $p_{E}$ and $p_{l_{i}}$, and correct for the endowment effects. If we use $S_{i j}$ as the substitution effect of the compensated demand for good $i$, when the price of good $j$ changes, inserting in equation (17) gives

$$
\begin{aligned}
A \cdot\left[\left(1-l_{1}+p X\right) p g(E) \cdot S_{l_{1} l_{2}}-p\left[g(E)\left(1-l_{2}\right)-X\right] \cdot S_{l_{1} l_{1}}\right] & +(26) \\
t_{2} W \cdot g(E) \cdot\left[\left(1-l_{1}+p X\right) p g(E) \cdot S_{l_{2} l_{2}}-p\left[g(E)\left(1-l_{2}\right)-X\right] \cdot S_{l_{2} l_{1}}\right] & + \\
B \cdot\left[\left(1-l_{1}+p X\right) p g(E) \cdot S_{E l_{2}}-p\left[g(E)\left(1-l_{2}\right)-X\right] \cdot S_{E l_{1}}\right] & + \\
\tau r \cdot\left[\left(1-l_{1}+p X\right) p g(E) \cdot S_{C_{1} l_{2}}-p\left[g(E)\left(1-l_{2}\right)-X\right] \cdot S_{C_{1} l_{1}}\right] & =0 .
\end{aligned}
$$

This can be seen as an adjusted restatement of equation (19) in Nielsen and Sørensen (1997), but equation (26) here contains a bit more information.

The first line in (26) incorporates distortions in the labor supply of unskilled workers, and the second line allows for tax-induced distortive effects in the labor market of skilled workers. While the third line is a restatement of the inelastic-labor-supply case (19), the fourth line calculates the distortions in intertemporal consumption, caused by the combination of capital income and labor taxation.

If we assume that leisure is an intertemporal substitute, $S_{l_{1} l_{2}}>0$, the first line is unambiguously positive, whilst the second line is negative in this case. As long as compensated first period consumption and compensated first period leisure are complements, $S_{C_{1} l_{1}} \leq 0$, whereas compensated first period consumption and compensated second period leisure are weakly substitutes, $S_{C_{1} l_{2}} \geq 0$, the fourth line will be positive.

If we furthermore assume that the substitution effects in second period 
leisure are small or approach zero, this requires the third line to be negative. As an increase in the skilled wage increases the return to education, we should have $S_{E l_{2}}>0$, and because an increase in the wage for unskilled labor increases opportunity costs of education, $S_{E l_{1}}<0$ seems to be reasonable. Taken together, the second term in the third line is positive, and we end up with

$B=(1+r)\left(W-w_{1}\right)-p_{B} / p+(1+r) p_{R}-\left(W-w_{2}\right) g^{\prime}(E) \cdot\left(1-l_{2}\right)+\tau r \cdot w_{1}<0$.

If we use the households first order condition (6), we can simplify equation (27) on the one hand to

$$
t_{2}-t_{1}>\frac{\tau r}{1+r} \cdot\left(1-t_{1}\right)-\frac{1+r(1-\tau)}{1+r} \cdot \frac{p_{B}}{W}+\frac{p_{R}}{W} \cdot\left(1-t_{2}\right) .
$$

Thus, given the assumptions above, progressive labor taxation in the presence of tuition fees is only optimal as long as capital income is taxed at a positive rate and tuition fees are not too high. Indeed, we should note that the tax structure can even turn regressive, if tuition fees are (very) high. In case of education subsidies, however, the labor tax schedule must be unambiguously progressive.

Compared to Nielsen and Sørensen (1997), it is not necessary to assume an additive utility function in order to derive these results.

On the other hand, equation (27) can be rearranged to get

$$
1+r<g^{\prime}(E) \cdot\left(1-l_{2}\right)-(1+r) \frac{p_{R}}{W} .
$$

The LHS is the marginal return to real capital, and the RHS gives the effective (social) marginal return to human capital. In the optimum, there is now underinvestment in education. The intuition is that, in case of (virtually) inelastic second period labor supply, the government can reach simultaneously two goals by using the surtax rate, $t_{2}$ : First, it can alleviate the excessive accumulation of human capital, which is caused by the capital income taxation, at no costs. Second, it can use the tax on skilled labor in order to 
collect tax revenue without much excess burden. This ends up in a high tax rate $t_{2}$, and in a reversal of the original overinvestment in education in case of $t_{1}=t_{2}$ and $p_{B}=0$.

Of course, inelastic second period labor supply is the most favorable environment in order to argue in favor of progressive labor taxation. If progressive taxation proves not to be optimal in such a setting, it should not be optimal in any case. As shown in the analysis above, there is a scope for progressive taxation, but this is again limited by tuition fees. In the other extreme, where labor supply of the young is inelastic, it can be shown that the results are even much less clear. However, progression can still prevail in some circumstances. More detailed results are derived in the following sections.

\section{Inelastic Youth Leisure}

If we assume that the leisure demand of young unskilled workers is inelastic, we can use $S_{l_{1 j}}=0$, and the symmetry of substitution effects, in order to reduce equation $(26)$ to

$$
B \cdot S_{E l_{2}}+t_{2} \cdot W \cdot g(E) \cdot S_{l_{2} l_{2}}+\tau r \cdot S_{C_{1} l_{2}}=0 .
$$

Again $B=\left[(1+r)-g^{\prime}(E) \cdot\left(1-l_{2}\right)+(1+r) \frac{p_{R}}{W}\right] \cdot W$ from using the household's first order condition (6).

If we use $S_{i j}=S_{j i}$ and $p_{C_{1}}=1$, we get as optimal tax and education policy rule

$$
\frac{p_{l_{2}}}{p_{E}}=\frac{p \cdot w_{2} \cdot g(E)}{w_{1}+p_{B}}=-\frac{t_{2} \cdot W \cdot g(E) \cdot \epsilon_{l_{2} l_{2}}+\tau r \cdot p_{l_{2}} \cdot \epsilon_{l_{2} C_{1}}}{\left[(1+r)-g^{\prime}(E) \cdot\left(1-l_{2}\right)+(1+r) \frac{p_{R}}{W}\right] \cdot W},
$$

whereby $\epsilon_{i j}$ denotes the compensated elasticity of demand for good $i$ according to a change in price of good $j$. Unfortunately, this optimality rule is hardly to interpret, especially with respect to the linkage of progressive taxation and tuition fees.

However, we can derive more clear-cut results, if we assume that the intertemporal utility function is additively separable between periods and 
compensated first period consumption does not react to changes in the price of second period leisure, implying $S_{C_{1} l_{2}}=0$. Returning to equation (30), an optimal solution is characterized by

$$
\frac{\epsilon_{E l_{2}}}{-\epsilon_{l_{2} l_{2}} \cdot \pi}=\frac{t_{2}}{(1+r)-g^{\prime}(E) \cdot\left(1-l_{2}\right)+(1+r) \frac{p_{R}}{W}},
$$

where $\pi=\frac{W \cdot g(E) \cdot\left(1-l_{2}\right)}{W \cdot E}$ represents average return (before taxes and fees) to wage income invested into eduction. Accordingly,

$$
\operatorname{sign}\left[\epsilon_{E l_{2}}\right]=\operatorname{sign}\left[(1+r)-g^{\prime}(E) \cdot\left(1-l_{2}\right)+(1+r) \cdot p_{R} / W\right] \quad \forall t_{2}>0,
$$

because $\epsilon_{l_{2} l_{2}}<0$. Again, $1+r-g^{\prime}(E) \cdot\left(1-l_{2}\right)+(1+r) \frac{p_{R}}{W}$ is the difference between marginal social return on real capital, which is exogenously determined by the world capital market, and effective marginal social return on human capital, which depends on the marginal productivity of its accumulation function, $g(E)$, and on labor supply in the second period, $\left(1-l_{2}\right)$.

Combining this result with condition (6) from the household's optimization problem, we end up with

$t_{2}-t_{1}\left(\begin{array}{c}< \\ >\end{array}\right)\left(1-t_{1}\right) \cdot \frac{\tau r}{1+r}-\frac{p_{B}}{W} \cdot \frac{1+r(1-\tau)}{1+r}+\frac{p_{R}}{W} \cdot\left(1-t_{2}\right), \quad$ if $\quad \epsilon_{E l_{2}}\left(\begin{array}{l}> \\ <\end{array}\right) 0$.

The most likely case and the most reasonable assumption are that the (compensated) demand for education increases, when the price for leisure, and hence the wage for skilled labor, increases. This implies $\epsilon_{E l_{2}}>0$. In this case, the optimal tax structure does not necessarily imply a progressive taxation of labor income, but this result can also not be precluded. ${ }^{16}$ Progressive taxation becomes more likely the higher the tax rate on capital income, $\tau$, is, and, therefore, the higher the induced distortions of real capital accumulation, and the lower tuition fees are. In any case, from (33) it follows that it is not optimal to eliminate overinvestment in human capital. The reason is that, compared to the last section, reducing education, especially via using

\footnotetext{
${ }^{16}$ The optimal labor taxation may also be either proportional or even regressive.
} 
a high surcharge tax, now causes severe distortions in the labor supply of skilled workers.

\section{Discussing the Optimal Tax Rule}

If we return to equation (32), we can see that, on the one hand, a higher skilled-wage elasticity of leisure demand, $\epsilon_{l_{2} l_{2}}$, calls ceteris paribus for a lower surcharge tax rate, $t_{2}$, and/or for more overinvestment in human capital. On the other hand, a higher skilled-wage elasticity of education demand, $\epsilon_{E l_{2}}$, calls for a higher tax rate $t_{2}$ and/or less investment in education.

The former effect mirrors induced distortions in labor supply and harms welfare. The latter effect is not necessarily that negative, because a tax induced reduction in education may enhance welfare, given the overinvestment in human capital caused by the real capital income tax, $\tau$. Hence, (32) represents a trade-off between the effect of skilled labor taxation on labor supply on the one hand and on education demand on the other hand. Not relevant for this optimal policy are substitution effects caused by the price for education, $p_{E}=w_{1}+p_{B}$. The reason is that these can be avoided, if necessary, because the standard tax rate, $t_{1}$, and tuition fees, $p_{B}$, are still equivalent instruments, although no longer perfect equivalent ones. They only differ in the income effect:

$$
\frac{\partial y}{\partial w_{1}}-\frac{\partial y}{\partial p_{B}}=(1+p X) \cdot \frac{\partial y}{\partial I}, \quad y \in\left(l_{2}, E, C_{1}\right) .
$$

Moreover, a combination of both instruments results in a lump-sum tax, and can affect all choice variables via a non-distorting income effect. However, this result is due to the setting of our model, where first period leisure demand is exogenous.

Taken together, we have four possible combinations of elasticities:

(i) If both relevant elasticities are high, the optimal policy mix can either be a high surtax, $t_{2}$, and large overinvestment in human capital, or a low surtax rate $t_{2}$, and little overinvestment. In the latter case, the society avoids strong labor supply distortions, and reduces education 
demand by setting a low standard rate, $t_{1}$, (thus, increasing $w_{1}$ ), and/or by using tuition fees, $p_{B}>0$. In the former case, the government trades distortions in labor supply against an effective reduction of education by lowering $w_{2}$. In order to alleviate the negative effects on labor supply, this has to be accompanied by stabilizing labor supply via lowering the price of education. ${ }^{17}$ Hence, high labor tax rates, progressive labor taxation, and tuition subsidies can also fulfill the optimality rule (32), although it appears a bit doubtful from an economic perspective.

(ii) Both elasticities are low. Then again, we have the two possible parameter constellation from case (i). Now, a high surcharge tax rate allows to finance the governmental budget without much distortions, whereas this has to be paid by accepting an inefficient high level of education. Moreover, tuition subsidies, $p_{B}<0$, may be necessary. If we take into account that in our model a lump-sum tax is available, this reasoning seems not to be very convincing. Therefore, it is more reasonable to expect that $t_{2}$ is small and overinvestment in human capital is dampened by an even lower standard tax rate, $t_{1}$, or by high tuition fees, $p_{B}$.

(iii) $\epsilon_{E l_{2}}$ is high, whereas $\epsilon_{l_{2} l_{2}}$ is low. The marginal tax rate $t_{2}$ is very effective in reducing education demand, but does not cause much labor supply distortions. Thus, $t_{2}$ should be high, and it should be accompanied by either a low standard rate, $t_{1}$, or by tuition fees, in order to guarantee a reduced human capital investment.

(iv) Education reacts only little on changes in the skilled after-tax wage rate, but labor supply is very wage-sensitive. Thus, the optimal tax rate $t_{2}$, should be low, and the level of overinvestment will be high. In this case, it is more of importance to alleviate labor supply distortions, which can be reached by a high standard tax rate, $t_{1}$ and/or no tuition fees or even tuition subsidies, $p_{B} \leq 0$, because of $\epsilon_{l_{2} E}>0$.

These results can be summarized as

\footnotetext{
${ }^{17}$ From the symmetry of substitution effects, $S_{i j}=S_{j i}$, follows $\epsilon_{l_{2} E}>0$, if $\epsilon_{E l_{2}}>0$.
} 
Tab. 1: Optimal tax rates and tuition fees, dependent on elasticities.

\begin{tabular}{|c|c|c|c|}
\hline & \multicolumn{2}{|c|}{ Elasticity of skilled labor } \\
\hline & & high & low \\
\hline \multirow{2}{*}{$\begin{array}{l}\text { Elasticity } \\
\text { of } \\
\text { education }\end{array}$} & high & $\begin{array}{l}\text { (ia) } t_{2}>t_{1} \text {, both low, } p_{B} \text { high } \\
\text { (ib) } t_{2} \geq t_{1} \text {, both high, } p_{B}<0\end{array}$ & (iii) $t_{2}>t_{1}, t_{2}$ high, $p_{B} \geq 0$ \\
\hline & low & $\begin{array}{c}\text { (iv) } t_{2} \leq t_{1}, p_{B} \leq 0 \\
t_{2} \text { low, } t_{1} \text { high or } p_{B}<0\end{array}$ & $\begin{array}{l}\text { (iia) } t_{2}>t_{1} \text {, both low, } p_{B} \text { high } \\
\text { (iib) } t_{2} \geq t_{1} \text {, both high, } p_{B} \leq 0\end{array}$ \\
\hline
\end{tabular}

In a nutshell, if either both elasticities are high or both are low, the optimal tax and education policy seems to be introducing a non-progressive labor taxation at low rates, and using tuition fees. If the elasticity of education with respect to the wage of a skilled worker is high, and the one of leisure is low, optimal tax rates are rather disjoint, and a progressive taxation is most likely. Moreover, tuition fees should not be very high, if there are any at all. In the opposite case, it seems even more likely to introduce education subsidies, if regressive taxation shall be avoided. This then implies at the most slight progression at modest tax rates.

Unfortunately, it is hard to get detailed empirical data on these elasticities. It seems that the elasticity of labor supply - especially the compensated one - is small. ${ }^{18}$ Thus, it should be justified to assume both unskilled and skilled labor supply as relatively inelastic. If so, cases (ii) and (iii) are of most relevance.

To get empirical results for the elasticity of learning with respect to the skilled wage is even more difficult. In Psacharopoulos (1973), the elasticity of freshman enrollment at public institutions for higher education in Hawaii for the years $1956-1968$ is found to be -1.12 w.r.t tuition fees and 0.45 w.r.t relative earnings of college graduates to high school graduates. If the latter is used as proxy for $\epsilon_{E l_{2}}$, this elasticity is also low, and at least for Hawaii case (ii) should apply to be optimal: moderate progression, but high tuition fees.

If we compare these results with our conclusions in the benchmark case

\footnotetext{
${ }^{18}$ An overview on some empirical studies for labor supply in the US and in Great Britain is given in Pencavel (1986).
} 
of inelastic second-period labor supply in section 5, we see that progressive taxation and tuition fees are still equivalent instruments, although no longer perfect ones. Moreover, most results are preserved in a qualitative sense, but the exact combinations of tax rates and tuition fees depend now on the elasticities, discussed above, and the requirements are much more restrictive. However, there is still strong support for either progressive taxation or tuition fees, and the simultaneity of progressive taxation and education subsidies as 'Siamese Twins' on pure efficiency grounds can also not be precluded, although labor supply is elastic, now. It seems that extending the Bovenberg/Jacobs (2005) approach for intertemporal consumption choice and distorting capital income taxation can preserve their result without making use of heterogenous households and equity concerns. Hence, we are still able to state that redistributive motives are sufficient, but not necessary for progressive taxation and education subsidies being 'Siamese Twins.'

To be precise, it is progression, who needs either indirect subsidies, where the educational sector is financed heavily from tax revenue $\left(p_{B}<p_{R}\right.$ or even $p_{B} \approx 0$ ), or who even needs direct subsidies, $p_{B}<0$, in order to survive with homogenous households. Subsidies itself can also appear in case of regressive taxation.

The indication for progressive taxation would be much stronger, if we assume $\epsilon_{E l_{2}}<0$. In this rather unrealistic and implausible case, where the level of compensated education demand depends negatively on the skill premium, we get from equation (33)

$$
(1+r)-g^{\prime}(E)\left(1-l_{2}\right)+(1+r) \frac{p_{R}}{W}<0 \quad \forall t_{2}>0
$$

and in combination with optimal behavior of the household, enforced underinvestment in human capital requires $t_{2}-t_{1}>0$ from (34), as long as the capital tax rate is positive and tuition fees are not too high. However, as mentioned, this scenario does not have any economic relevance.

In comparison to the approach by Nielsen and Sørensen (1997), we have chosen a model, where the standard tax rate, $t_{1}$, does not have a direct effect on the labor supply, whereas the surcharge tax, $t_{2}$, causes strong distortions 
of labor supply. This is perhaps the worst environment in order to argue in favor of progressive labor taxation. Whilst Nielsen and Sørensen (1997, p. 325) focus on the argument that young unskilled workers are rather elastic in labor supply, whereas older workers have to finance their families, and are faced by higher opportunity costs of leisure due to their skills, we take the opposite view. Being full time student does not leave much time for work, and this must be used in order to finance subsistence consumption. When they leave universities as 'high-potentials,' they are much more wagesensitive than unskilled workers. At least, this argument is at the heart of the justifications for many tax reforms lowering the high surcharge tax rates.

In spite of this setting, we cannot rule out the optimality of a progressive (labor) tax structure. Although the requirements for it are much more restrictive, our analysis shows that the Nielsen and Sørensen result must not be seen as a third best result. It is not due to abstracting from an educational sector and neglecting the possibility of tuition fees, which are sometimes seen as superior instrument to handle excessive human capital accumulation. However, tuition fees limit the scope of progressive taxation significantly, and the optimal combination depends on the magnitude of the labor supply and the education demand elasticities.

A possible extension of the model can be to introduce capital market imperfections. Subsidizing education can then be optimal to overcome these frictions, when the young generation is not able to borrow against future labor income or has to pay higher interest rates than the social intertemporal price $r$. Suboptimal low investment in education can then be avoided by using a front-load subsidy and a back-load progressive taxation system. Given our result that both instruments are equivalent, the welfare costs of such a strategy could be lower than expected at first glance.

\section{Conclusions}

We have shown that the Nordic dual income tax system can be optimal, even if a price for human capital investment is introduced in the analysis by Nielsen and Sørensen (1997). However, progressive labor taxation is not the 
only optimal tax system, as tuition fees and progressive taxation are equivalent instruments. The former directly discourages investment in education, therefore lowers the effective wage rate for skilled workers and, hence, their opportunity costs of leisure. This leads indirectly to reduced skilled labor supply. The latter reduces the skilled wage rate and labor supply by skilled workers directly, hence reduces the return to human capital investment, and therefore also discourages investment in education. The optimal policy mix then depends on the elasticities of leisure and education demand. Moreover, education subsidies and progressive taxation can be 'Siamese Twins' on pure efficiency grounds, without using any redistributive argument.

These results must be kept in mind, if any reform in financing the educational sector is considered. Given the starting point was optimal, the introduction of tuition fees must have an effect on the labor tax schedule. This seems not to be the case for the Central European countries and for the U.K. Consequently, their latest reform steps might appear doubtful. On the other hand, the US-way would fit to the case, where either the elasticities of labor supply and education demand are either both low or both high, whereas the Nordic way would fit to the case of low elasticities in labor supply, but highly elastic education demand.

Ongoing work should try to link empirical observations on the compensated elasticities of leisure and education with the tax and education policies, described above. This might allow to test our model. On the theoretical side, a major feature, which is neglected, is uncertainty of success in human capital investment and stochastic labor income of high-educated worker (see, e.g., Wigger and von Weizsäcker, 2001; Anderberg and Andersson, 2003). Labor taxation can then have an insurance effect and taken together with education subsidies, this policy instrument is very similar to the approach by Eaton and Rosen (1980a, 1980b). 


\section{Appendix}

Given inelastic leisure demand, $l=0$, and $X=1$, the first order conditions of the household can be reduced to

$$
\begin{aligned}
1 / p \cdot U_{2}-U_{1} & =0, \\
-w_{1}+p \cdot w_{2} \cdot g^{\prime}(E)-p_{B} & =0, \\
C_{1}+p \cdot C_{2}-w_{1} \cdot(1-E+p)-p \cdot w_{2} \cdot[g(E)-1]+p_{B} \cdot E & =0 .
\end{aligned}
$$

Differentiating totally, collecting terms and using the second FOC (38) gives

$$
\begin{gathered}
\left(\begin{array}{ccc}
1 / p \cdot U_{21}-U_{11} & 1 / p \cdot U_{22}-U_{12} & 0 \\
0 & 0 & p \cdot w_{2} \cdot g^{\prime \prime} \\
1 & p & 0
\end{array}\right)\left(\begin{array}{c}
d C_{1} \\
d C_{2} \\
d E
\end{array}\right) \\
\quad=\left(\begin{array}{c}
0 \\
1 \\
1-E+p
\end{array}\right) d w_{1}+\left(\begin{array}{c}
0 \\
-p \cdot g^{\prime} \\
p \cdot(g(E)-1)
\end{array}\right) d w_{2}+\left(\begin{array}{c}
0 \\
1 \\
-E
\end{array}\right) d p_{B}
\end{gathered}
$$

Hence, the original determinant can be displayed as

$$
\operatorname{det}_{H}=p \cdot w_{2} \cdot g^{\prime \prime}(E) \cdot\left[\left(1 / p \cdot U_{22}-U_{12}\right)-p \cdot\left(1 / p \cdot U_{21}-U_{11}\right)\right] .
$$

We get as modified determinants

$$
\begin{aligned}
& \operatorname{det}_{C_{1} w_{2}}=\left(1 / p \cdot U_{22}-U_{12}\right) \cdot p^{2} \cdot w_{2} \cdot g^{\prime \prime} \cdot[g(E)-1], \\
& \operatorname{det}_{C_{1} w_{1}}=\left(1 / p \cdot U_{22}-U_{12}\right) \cdot p \cdot w_{2} \cdot g^{\prime \prime} \cdot(1-E+p), \\
& \operatorname{det}_{C_{1} p_{B}}=-\left(1 / p \cdot U_{22}-U_{12}\right) \cdot p \cdot w_{2} \cdot g^{\prime \prime} \cdot E .
\end{aligned}
$$

Using Cramer's rule, these imply

$$
\begin{aligned}
\left.(1+p) \cdot \frac{\partial C_{1}}{\partial w_{2}}-p \cdot[g(E)-1)\right] \cdot\left(\frac{\partial C_{1}}{\partial w_{1}}-\frac{\partial C_{1}}{\partial p_{B}}\right) & = \\
\frac{(1+p) \cdot \operatorname{det}_{C_{1} w_{2}}-p \cdot[g(E)-1] \cdot\left(\operatorname{det}_{C_{1} p_{B}}-\operatorname{det}_{C_{1} p_{B}}\right)}{\operatorname{det}_{H}} & =0
\end{aligned}
$$


because

$$
\operatorname{det}_{C_{1} p_{B}}-\operatorname{det}_{C_{1} p_{B}}=p \cdot w_{2} \cdot g^{\prime \prime}(E) \cdot(1+p) \cdot\left(1 / p \cdot U_{22}-U_{12}\right) .
$$

Moreover, we receive

$$
\begin{aligned}
\operatorname{det}_{E w_{2}} & =-\left(1 / p \cdot U_{22}-U_{12}\right) \cdot p \cdot g^{\prime}+\left(1 / p \cdot U_{21}-U_{11}\right) \cdot p^{2} \cdot g^{\prime} \\
\operatorname{det}_{E w_{1}} & =\left(1 / p \cdot U_{22}-U_{12}\right)-\left(1 / p \cdot U_{21}-U_{11}\right) \cdot p, \\
\operatorname{det}_{E p_{B}} & =\left(1 / p \cdot U_{22}-U_{12}\right)-\left(1 / p \cdot U_{21}-U_{11}\right) \cdot p,
\end{aligned}
$$

and thus, as expected,

$$
\begin{aligned}
\frac{\partial E}{\partial w_{2}} & =-\frac{p \cdot g^{\prime}(E)}{p \cdot w_{2} \cdot g^{\prime \prime}(E)}>0, \\
\frac{\partial E}{\partial w_{1}} & =\frac{\partial E}{\partial p_{B}}=\frac{1}{p \cdot w_{2} \cdot g^{\prime \prime}(E)}<0,
\end{aligned}
$$

from Cramer's rule again.

\section{References}

Anderberg, D., and F. Andersson, 2003. Investments in Human Capital, Wage Uncertainty, and Public Policy. Journal of Public Economics 87, $1521-1537$.

Atkinson, A.B., and A. Sandmo, 1980. Welfare Implications of the Taxation of Savings. Economic Journal 90, 529-549.

Bovenberg, A.L., and B. Jacobs, 2001. Redistribution and Education Subsidies are Siamese Twins. CEPR Working Paper No. 3309, London.

Bovenberg, A.L., and B. Jacobs, 2005. Redistribution and Education Subsidies are Siamese Twins. Journal of Public Economics 89, 2005-2035.

Diamond, P.A., and J.A. Mirrlees, 1971. Optimal Taxation and Public 
Production 1: Production Efficiency and 2: Tax Rules. American Economic Review 61, 8-27 and 261-278.

Eaton, J., and H.S. Rosen, 1980a. Labor Supply, Uncertainty, and Efficient Taxation. Journal of Public Economics 14, 365-374.

Eaton, J., and H.S. Rosen, 1980b. Taxation, Human Capital, and Uncertainty. American Economic Review 70, 705-715.

Echevarria, C.A., and A. Iza, 1997. Comprehensive Income Taxation, Investments in Human and Physical Capital, and Productivity: A Note. Journal of Public Economics 65, 387-394.

García-Peñalosa, C., and K. Wälde, 2000. Efficiency and Equity Effects of Subsidies to Higher Education. Oxford Economic Papers 52, 702-722.

Jacobs, B., and A.L. Bovenberg (2005). Human Capital and Optimal Positive Taxation of Capital Income, Tinbergen Institute Discussion Paper 05-035/3.

Nerlove, M., A. Razin, E. Sadka, and R.K. von Weizsäcker, 1993. Comprehensive Income Taxation, Investments in Human and Physical Capital, and Productivity. Journal of Public Economics 50, 397-406.

Nielsen, S.B., and P.B. Sørensen, 1997. On the Optimality of the Nordic System of Dual Income Taxation. Journal of Public Economics 63, 311-329.

Pencavel, J., 1986. Labor Supply of Men: A Survey. In: O. Ashenfelter, and R. Layard (eds.), Handbook of Labor Economics Vol. 1, Amsterdam, $3-102$.

Psacharopoulos, George, 1973. A Note on the Demand for Enrollment in Higher Education. De Economist 121, NR. 5, 521-525.

Rose, M., 1999. Recommendations on Taxing Income for Countries in Transition to Market Economies. M. Rose (ed.), Tax Reform for Countries in Transition to Market Economies. Lucius \& Lucius, Stuttgart. 
Trostel, P.A., 1996. Should Education be Subsidized? Public Finance Quarterly $24,3-24$.

Wigger, B.U., 2004. Are Higher Education Subsidies Second Best? Scandinavian Journal of Economics 106. 65-82.

Wigger, B.U., and R. von Weizsäcker, 2001. Risk, Resources, and Education - Public versus Private Financing of Higher Education. IMF Staff Papers 48, 547-560.

Wildasin, D., 2000. Labor-market Integration, Investment in Risky Human Capital, and Fiscal Competition. American Economic Review 90, 7395. 